\title{
«FRANCÉS DE NACIÓN, VARÓN DOCTÍSSIMO»: DIOGO SIGEU, PAI DE LUÍSA SIGEIA
}

\author{
Catarina Monteiro ${ }^{1}$ \\ (Universidade Nova de Lisboa) \\ catarina.monteiro1@,gmail.com
}

\section{RESUMO}

Neste artigo, propomo-nos a apresentar uma análise profunda, baseada em novos dados, da figura de Diogo Sigeu, pai de Luísa Sigeia (1522-1560), escritora espanhola que viveu entre os dois reinos da Península Ibérica. Apesar de ser uma figura bastante reconhecida pelos seus conterrâneos e amplamente conhecida da historiografia actual (principalmente a espanhola), as origens familiares da poliglota são vagamente conhecidas e até algo abstractas. Ainda que existam alguns dados mais ou menos sólidos referentes à vida de Diogo nos seus primeiros anos em Portugal, conseguimos elaborar uma nova hipótese biográfica, à luz de novos dados e de uma releitura atenta das fontes, que nos mostra muito mais sobre a sua escondida personalidade humanista.

PALAVRAS-CHAVE: Luísa Sigeia (1522-1560); Diogo Sigeu; biografia.

\section{«FRANCÉS DE NACIÓN, VARÓN DOCTÍSSIMO»: DIEGO SIGEO, LUISA SIGEA'S FATHER}

\begin{abstract}
In this article, we propose to present a deeper analysis, based on new data, of the figure of Diogo Sigeu, the father of Luísa Sigeia (1522-1560), Spanish writer who lived between the two Iberian kingdoms. Despite being a well recognized figure by her contemporaries and widely known by current historiography (especially the Spanish one), the polyglot's familiar origins are vaguely known and even somewhat abstract. Although there is some sort of solid data regarding Diogo's first years in Portugal, we have been able to elaborate a new biographical hypothesis, under the lights of new data and an attentive re-reading of the sources, that shows us much more about his hidden humanistic personality.
\end{abstract}

\footnotetext{
${ }^{1} \mathrm{O}$ presente artigo corresponde, com as devidas alterações, a um subcapítulo da nossa dissertação de Mestrado: C. Monteiro, “Quando as sombras ofuscam a luz. Luísa e Ângela Sigeia: estórias e histórias de vida no Portugal de Quinhentos" (Dissertação de Mestrado, Faculdade de Ciências Sociais e Humanas, Universidade Nova de Lisboa, 2019), 24-49. A autora não segue o Acordo Ortográfico da Língua Portuguesa de 1990.
} 
KEY WORDS: Luisa Sigea (1522-1560), Diego Sigeo, biography.

\section{NOTA INTRODUTÓRIA: UM RESUMO BIOGRÁFICO DE LUÍSA SIGEIA}

Luísa Sigeia (1522-1560) é, talvez, uma das mulheres eruditas quinhentistas mais controversas biograficamente. Desconhece-se o seu ano e local de nascimento exactos, ignora-se a forma como passou a infância e adolescência, não se tem certezas sobre quando se terá mudado para Portugal, nem é claro qual o ano do seu regresso a Espanha $^{2}$. Da mesma forma, também os seus ascendentes estão envoltos numa corrente de incerteza, carregando em si mesmos um pesado silêncio sobre as suas vidas. Antes de abordarmos a figura paterna, porém, parece-nos útil fazer uma súmula biográfica desta poliglota quinhentista.

Tendo muito provavelmente nascido no ano de 1522 (ou antecedente), em Tarancón (pertencente, na época, ao reino de Toledo ${ }^{3}$ ), Luísa seria a terceira dos quatro filhos de Diogo Sigeu e D. Francisca de Velasco, uma figura pertencente, muito provavelmente, a uma família da alta nobreza castelhana (os Velasco) ${ }^{4}$. Nesse início da década de vinte, teriam já nascido Diogo (talvez em 1511), o primogénito, e António (1517?-1575). A irmã Ângela, figura quase obliterada da historiografia, seria mais nova do que a erudita, conhecendo-se apenas a sua data de falecimento (1608).

Permanecendo os primeiros anos de vida junto da mãe e dos irmãos em Tarancón, onde terá contactado com as primeiras letras, pensamos que Luísa e o resto da família terão vindo para Portugal no ano de 1530, para se juntarem ao pai, que se encontrava no reino desde 1522. Num primeiro momento, a jovem terá crescido em

\footnotetext{
${ }^{2}$ Sobre algumas das ideias biográficas de Luísa, elaboradas mais recentemente, cf. Nieves Baranda, "Luisa Sigea: la brillante excepción femenina", in Melchor Cano y Luisa Sigea: dos figuras del Renacimiento Español, coord. Miguel Ángel Pérez Priego (Tarancón: Ayuntamiento de Tarancón / UNED, 2008), 129-152; María Regla Prieto Corbalán, Luisa Sigea y su mundo: epistolario latino (Madrid: Akal, 2007); Raúl Amores Pérez, "Biografía de Luisa Sigea Toledana. Una taranconera del siglo XVI en la corte portuguesa y española", in Melchor Cano y Luisa Sigea: dos figuras del Renacimiento Español, coord. Miguel Ángel Pérez Priego (Tarancón: Ayuntamiento de Tarancón / UNED, 2008), 167-265; Amores Pérez, "Luisa Sigea de Tarancón y la Infanta Doña María de Portugal: «amiticia» entre desiguales, aprendizaje en común", in Catálogo de Obras de Luisa Sigea de Velasco, Virginia Garrido de la Torre (trad.), Raúl Amores Pérez e Jesús Garrido Gallego (Tarancón: Ayuntamiento de Tarancón, 2017), 11-42; I. Mareñà, "Luisa Sigea de Velasco: reflexions filosòfiques d'una docta puella espanyola del segle XVI" (Tese de Doutoramento, Universitat de Girona, 2014), 119-128.

${ }^{3}$ María Dolores Gomez Molleda, "La cultura femenina en la epoca de Isabel la Catolica. Cortejo y estela de una reina", Revista de Archivos, Bibliotecas y Museos, tomo LXI, núm. 1 (1955): 192; Prieto Corbalán, Luisa Sigea y su mundo, 55, nota 193.

${ }^{4}$ Sobre D. Francisca de Velasco, para quem também desenvolvemos uma narrativa biográfica, cf. Monteiro, "Quando as sombras ofuscam a luz", 49-70.
} 
terras alentejanas, mais concretamente, no Paço Ducal de Vila Viçosa, na corte da Casa de Bragança, para quem trabalhava Diogo Sigeu. Seria aí que a jovem aprenderia as línguas clássicas e orientais, sob a orientação directa do pai, no mesmo universo em que desenvolveria os primeiros laços cortesãos. A propósito do casamento, em 1537, entre a infanta-duquesa D. Isabel (antes de 1512-1576) e o infante D. Duarte (15151540), irmão do rei D. João III (1502-1557), Luísa e a irmã Ângela seriam integradas no séquito da noiva, mudando-se com ela de Évora para Lisboa, acompanhando a corte régia.

Em Lisboa, as duas irmãs passariam da Casa da infanta-duquesa para a Casa da rainha D. Catarina de Áustria (1507-1578), possivelmente antes do ano de 1540. Foi ao serviço de D. Catarina que as duas mulheres iluminaram a corte portuguesa, caminhando frequentemente entre a Casa da rainha e a Casa da infanta D. Maria (15211577), irmã do rei, onde Luísa desenvolveu os seus trabalhos (o poema Syntra, de 1546, e o Duarum virginum colloquium de vita aulica et privata, de 1552) e escreveu grande parte das suas cartas. Seria também neste ambiente que as duas irmãs se separariam. Luísa ter-se-á mantido na corte até meados da década de 1550, abalando, depois, para Burgos com o marido, Francisco de Cuevas (1519/20-1599), onde faleceria em 1560. Ângela, por outro lado, ter-se-á mantido no meio cortesão até, pelo menos, depois da década de 1550. A historiografia convencionou que a música abandonara a corte ao mesmo tempo que a irmã latinista, mudando-se para Torres Novas, em Santarém, com o marido, Antão Mogo de Melo (†1592), em meados do século. Porém, novos dados, que se prendem com a acção mecenática de Ângela, criaram a possibilidade de esta ter permanecido, fisicamente, na corte da Sereníssima infanta D. Maria até aos meados da década de 1560, sendo que, depois de deixar Lisboa e se fixar em Torres Novas, conseguiu manter a ligação com esses círculos de poder, principalmente com a Casa de Bragança, na pessoa da duquesa D. Catarina (1540-1614), com quem se terá intensamente carteado ${ }^{5}$.

Em Burgos, Luísa deu à luz a única filha, Juana (1557-1593), tendo sido mestra latina na Casa de Maria da Hungria, regente dos Países-Baixos, nos últimos meses da sua vida, em 1558, onde também o seu marido foi admitido como secretário. Após a morte da rainha, Luísa procurou trabalho na corte de Filipe II, mas nunca obteve resposta. Tendo escrito mais de duas dezenas de cartas latinas e castelhanas a homens e mulheres dos grandes círculos cortesãos do seu tempo, Luísa faleceria a 13 de Outubro de 1560, em Burgos, sem manter ligações activas com nenhum desses meios.

O traçar desta biografia é essencial para compreender as hipóteses que lançamos sobre a vida do seu ascendente paterno, Diogo Sigeu. Também este personagem está envolto numa corrente de incerteza. Ou, melhor dizendo, também a origem do patriarca tem sido questionada pelos estudiosos. No entanto, cremos que os contactos que Luísa (tal como os irmãos e irmã) desenvolveu na corte portuguesa e na corte espanhola foram possibilitados pela posição social que o seu pai ocupou antes, durante e depois do seu nascimento, infância e adolescência, sendo que o caminho que

\footnotetext{
${ }^{5}$ Sobre os novos dados relativos à vida de Ângela, cf. Monteiro, "Quando as sombras ofuscam a luz", 143-146.
} 
a latinista trilhou enquanto adulta se deve, essencialmente, a esses laços previamente engendrados.

\section{DIOGO SIGEU}

\subsection{Do Berço a Portugal}

A naturalidade de Diogo Sigeu (que espelhámos no título com uma citação de Fernández Bethencourt ${ }^{6}$ ), tal como a da filha, foi já muito discutida. A questão ainda não está, contudo, fechada, pois não existe até hoje um consenso entre a origem francesa ou espanhola do humanista ${ }^{7}$. No entanto, consideramos que o pai (e principal preceptor) de Luísa nasceu em França, segundo atestam as provas de nobreza e limpeza de sangue datadas de 1622 e 1626, de dois dos netos da latinista, Francisco e Gonzalo Ronquillo ${ }^{8}$, filhos da sua única filha, Juana, para ingressar na Ordem Militar de Santiago. Seguimos, por isso, a hipótese de que Diogo Sigeu era francês e que, a certa altura (talvez quando se inscreveu na Universidade de Alcalá de Henares), se mudou para Espanha, onde incorporou o epíteto de «toledano». Sabe-se que o humanista terá nascido em finais do século XV, desconhecendo-se os seus progenitores. Em 1510 ${ }^{9}$, casou com D. Francisca de Velasco, oriunda da nobreza castelhana. O enlace gerou dois filhos e duas filhas: Diogo, António, Luísa e Ângela ${ }^{10}$. Sigeu teve formação universitária (línguas clássicas e orientais) em Alcalá de Henares, onde poderá ter conhecido André de Resende, que frequentou a mesma universidade $^{11}$. Foi aluno de grandes nomes do meio humanista, como Antonio de Nebrija (1442-1522), o grego Demetrio Ducas (1480-1527) e o judeu converso Alonso

${ }^{6}$ Francisco Fernández Bethencourt, Historia genealógica y heráldica de la monarquia española, Casa Real y Grandes de España (Madrid: Establecimiento Tipográfico de Enrique Teodoro, 1901), tomo III, 93. 119.

7 O debate historiográfico prolongou-se, pelo menos, até 2014. Cf. Mareñà, "Luisa Sigea de Velasco",

8 Os documentos a que se refere Férnandez Bethencourt são os seguintes: "Pruebas para la concesión del Título de Caballero de la Orden de Santiago de Francisco Ronquillo de Cuevas, natural de Arévalo" (1622) e "Pruebas para la concesión del Título de Caballero de la Orden de Santiago de Gonzalo Ronquillo de Cuevas, natural de Burgos" (1626). Os expedientes do primeiro dos dois documentos, referentes a D. Francisco, foi publicado, na íntegra, por Ismael García Rámila. Cf. "Expediente de pruebas de nobleza y limpieza de sangre, incoado para el ingreso en la Orden Militar de Santiago de los hermanos D. Francisco e D. Gonzalo Ronquillo de Cuevas", in Ismael García Rámila, "Nuevas e interesantes noticias, basada en fe documental, sobre la vida y descendencia familiar burgalesa de la famosa humanista, Luisa de Sigea, la «Minerva» de los renacentistas", in Boletín de la Institución Fernán González, no 147 (1959): 577-581; edição de que aqui nos servimos também para outros documentos.

9 Pérez Ramírez é o único autor que aponta uma data para o matrimónio do humanista (cf. Dimas Pérez Ramírez, Tarancón en la Historia. I. Desde la Romanización hasta el final del Antiguo Régimen (Tarancón: Antona, 1994), 161), sendo seguido por Amores Pérez (cf. Amores Pérez, "Biografía de Luisa Sigea Toledana", 204).

${ }^{10}$ Sobre a descendência masculina do casal, cf. Monteiro, "Quando as sombras ofuscam a luz", 7077.

${ }^{11}$ Cf. Paul Teyssier, "L'Humanisme portugais et l'Europe", in L' Humanisme Portugais et l' Europe. Actes du XXIe Colloque International d'Études Humanistes (Paris: Fondation Calouste Gulbenkian / Centre Culturel Portugais, 1984), 825. 
de Zamora (c. 1476-1544), professor de hebraico. Estes três mestres ${ }^{12}$ instalaram-se na Universidade de Alcalá entre os anos de 1512 e $1514^{13}$. Portanto, Sigeu, que, segundo as suas próprias palavras, teve como preceptores estes três eruditos ${ }^{14}$, terá frequentado a universidade durante esses anos. Confirmando-se a data do seu casamento em 1510, então a sua formação universitária esteve ligada aos seus primeiros anos de matrimónio com D. Francisca.

Desconhece-se o ano em que o humanista entrou ao serviço de D. María Pacheco (c. 1496-1531), uma mulher oriunda da mais alta nobreza castelhana que se revelaria uma destacada protagonista dos tumultos políticos e sociais ocorridos em Castela, na segunda década de Quinhentos: a revolta das Comunidades (1520-1521).

D. María Pacheco nasceu em Granada, filha de Francisca Pacheco $(† 1507)$ e de Iñigo López de Mendoza (c. 1442-1515), II conde de Tendilla, I marquês de Mondéjar e vice-rei de Granada desde 1492. Do lado materno, era também sobrinha do marquês de Villena, Juan Pacheco de Luna. Ao lado da irmã e dos irmãos, D. María teve uma esmerada educação humanista, proporcionada por mestres que o seu pai trouxera do estrangeiro para a instrução dos seus filhos, como Pedro Mártir de Anghiera (c. 14561526) ${ }^{15}$ e Hernán Núñez de Toledo (c. 1478-1553) ${ }^{16}$. Ao que parece, D. María Pacheco

\footnotetext{
12 Os três foram autores da Biblia Políglota Complutense, projecto levado a cabo por Francisco Jiménez de Cisneros, mais conhecido como cardeal Cisneros, para elaborar uma Bíblia multilingue. O projecto começou em 1502/1503 e a primeira impressão data de 1514. Cf. Maribel Manzano García, "Revisión de las noticias sobre libros, imprentas, bibliotecas y archivos, dadas por Antonio Ponz en su obra: viage [sic] de España", Papeles Salmantinos de Educación 2 (2002): 188. O projecto juntou também outros nomes, como Pablo Coronel ou Diego de Zúñiga/Estúñiga. Cf. Pérez Ramírez, Tarancón en la Historia, 161.

13 Zamora começou como catedrático de hebraico em 1512 (cf. María Fuencisla García Casar, "Alonso de Zamora", Real Academia de la Historia: Diccionario electrónico; http://dbe.rah.es/biografias/6393/alonso-de-zamora) e Nebrija, já numa idade bastante avançada, tomou posse da cátedra de Retórica em 1513 (cf. Asunción Rallo Gruss, La prosa didáctica en el siglo XVI, [Madrid: Taurus, 1987], 22). Desconhecemos o ano em que Demetrio Ducas entrou ao serviço da Universidade de Alcalá, mas poderá ter sido em 1514 ou num ano anterior, pois, como já referimos, também ele esteve ligado ao projecto linguista de Cisneros, cuja primeira impressão saiu precisamente nesse ano de 1514.

${ }^{14}$ Estas suas palavras, citadas por Asenjo Barbieri, integram uma obra sua publicada em 1560 e dedicada ao cardeal-infante D. Henrique, irmão de D. João III. Esta obra é um género de opúsculo ou adenda a uma outra obra da sua autoria, assinada em 1557. A referida citação é a seguinte:

«Tratando de los autores á quien sigue, cita entre los latinos: "Nebrissensem praeceptorem meum»; nombra despues algunos griegos, y añade: «Et vivae vocis praeceptorem meum in schola Complutensi Demetrium Ducam natione graecum, patria Cretensem»; finalmente, cita los hebreos, añadiendo: «Sed vivae vocis Praeceptores Zamoram, Paulum Cornelium Burgensem, Stunicam Doctores Complutenses"» (Francisco Asenjo Barbieri, "Una obra de Diego Sigeo", Boletin Histórico 4 [1880]: 54).

${ }^{15}$ Humanista italiano trazido por Íñigo López de Mendoza, seu patrono, para Castela, onde serviu na corte dos Reis Católicos durante largos anos. Sobre a sua vida, cf. Luis Arranz Márquez, "Pedro Mártir de Anglería", Real Academia de la Historia: Diccionario electrónico; http://dbe.rah.es/biografias/10770/pedro-martir-de-angleria (consultado a 10 de Maio de 2019).

${ }^{16}$ De acordo com o seu próprio testemunho, Hernán Núñez tinha ligações com Aires Barbosa, catedrático de Grego na universidade de Salamanca, e Antonio de Nebrija, a quem já nos referimos. O conde de Tendilla chamou-o para educar o seu primogénito, D. Luis Hurtado de Mendoza, o irmão mais velho de D. María Pacheco, nomeando-o seu preceptor em 1499. Segundo consta, Hernán Núñez serviria também como um agente cultural, tendo feito duas viagens a Itália, «que le sirvieron para
} 
e a sua irmã, D. María de Mendoza $^{17}$, participavam num círculo literário influenciado pelo ideal de educação feminina despertado por Isabel a Católica (1451-1504) ${ }^{18}$.

Em 1515, casou com Juan de Padilla (1490-1521), filho de Pedro López de Padilla e sobrinho do comendador maior de Calatrava, Gutierre López de Padilla ${ }^{19}$. D. María, o seu marido e o único filho de ambos, Pero López de Padilla (1516/7-1523) ${ }^{20}$, mudaram-se de Granada para Toledo em 1518 e poderá ter sido nessa altura - e talvez querendo encontrar um possível mestre de línguas clássicas para o filho - que os futuros líderes comuneros incluíram Sigeu na sua Casa. À sua senhora, Diogo ensinou latim (que era já familiar a D. María) e grego ${ }^{21}$, matérias que ensinaria anos mais tarde em Vila Viçosa, na corte da Casa de Bragança, aos filhos do duque D. Jaime (1479$1532)^{22}$.

\subsection{A passagem e o estabelecimento em terras portuguesas}

Infelizmente, são estas as únicas informações que temos sobre a vida do humanista até 1522, ano marcado pelo seu exílio forçado de Castela. Referimo-nos à sua vinda para Portugal no séquito da fugitiva D. María Pacheco, aquando do desenlace da revolta das Comunidades ${ }^{23}$. Após tentativas para evitar a execução da líder comunera, que permanecia na casa que convertera em fortaleza militar, a solução foi, de facto, a fuga para Portugal ${ }^{24}$. Nesta evasão, a viúva de Padilla foi acompanhada por vários dos seus

completar su formación humanística y para comprar libros [...] a su protector». Em 1513, foi para a universidade de Alcalá de Henares, onde colaborou na feitura da Biblia Políglota. Em 1519, sucedeu a Demetrio Ducas, na cátedra de Grego da mesma universidade. Cf. Teresa Jiménez Calvente, "Hernán Núñez de Guzmán", Real Academia de la Historia: Diccionario electrónico; http://dbe.rah.es/biografias/21505/hernan-nunez-de-guzman (consultado a 10 de Maio de 2019).

${ }_{17}$ Condessa de Monteagudo, pelo seu casamento com Antonio de Mendoza.

${ }^{18}$ Cf. Stephanie Fink de Backer, "Rebel with a Cause: The Marriage of María Pacheco and the Formation of the Mendoza Identity", in Power and Gender in Renaissance Spain. Eight Women of the Mendoza Family, 1450-1650, ed. Helen Nader (Urbana and Chicago: University of Illinois Press, 2004), 72. É elucidativa a nota referente a esta questão, onde se evidencia a diferença no propósito da educação das mulheres:

«While Isabelline model called for a feminine, passive, and private learned woman, María Pacheco did not follow this path. It is in part because of her transgression of the cultural norm set by Isabel for aristocratic women that María was so highly criticized by male contemporaries for "acting like a man"» (Ibidem, 85, n. 8).

${ }^{19}$ Cf. Ibidem, 73-75.

${ }^{20}$ Cf. Ibidem, 80.

21 «Fue mi Señora Doña María Pacheco muy docta en latín y en griego y mathemática [...]» ("Relación..." in Amores Pérez, "Biografía de Luisa Sigea Toledana", 202).

22 Falaremos desta figura mais adiante.

${ }_{23}$ Para se compreender, de forma breve, os inícios da revolta das Comunidades, cf. Joseph Pérez, José Antonio Maravall e Julio Valdeón Baruque, "Los comuneros", Historia 1624 (1978): 67-94. Contudo, mantém-se indispensável a consulta do pioneiro e aprofundado estudo de Joseph Pérez. Cf. Joseph Pérez, La revolution des "Comunidades" de Castille (1520-1521) (Bordeaux: Institut d' Études Ibériques et Ibero-Americaines de l'Université, 1970).

${ }^{24}$ Cf. Ibidem, 381-383. 
servidores, onde se incluía o seu preceptor, Diogo Sigeu ${ }^{25}$. A entrada em território português foi feita por Castelo Branco, a 3 de Fevereiro de $1522^{26}$, tendo a comitiva de D. María percorrido, durante cerca de três meses, as cidades da Guarda, Viseu e Porto. Por fim, a viúva e o seu séquito foram acolhidos em Braga, por D. Diogo de Sousa, arcebispo da cidade, onde permaneceram «tres o cuatro años [estando D. María] muy doliente $»^{27}$. Poderá ter sido, talvez, nesta cidade que Sigeu iniciou a sua carreira pedagógica, apesar da condição de saúde da sua senhora ${ }^{28}$.

Por esta altura, já a Coroa castelhana decretara um perdão geral a membros participantes e/ou coniventes com a revolta ${ }^{29}$, numa tentativa de reconciliação com a nobreza e a oligarquia urbana, reconciliação necessária para a legitimação do novo rei Habsburgo. Muitos servidores de D. María Pacheco lograram os perdões oferecidos pelo rei-imperador e regressaram a Castela, abandonando a líder comunera. Simultaneamente, o novo monarca emitia decretos exigindo a deportação de elementos insurrectos que se tivessem evadido para terras lusas, procurando refúgio no reino vizinho.

Apesar da insistência por parte de Carlos V, D. João III (1502-1557), que, entretanto, subira ao trono por morte do pai, D. Manuel, falecido em Dezembro do ano anterior, não agiu activamente para extraditar os exilados políticos, como D. María Pacheco, do reino ${ }^{30}$. O monarca português assinou um decreto que proibia o acolhimento destes fugitivos, mas nunca terá tido intenções de aplicá-lo, atitude sustentada pelas cartas particulares que escreveu às cidades para que ninguém fosse perseguido $^{31}$. Ao contrário do que fizera com outros personagens da revolta das

${ }^{25} \mathrm{D}$. María foi uma das muitas personalidades a procurar refúgio em terras lusas, no fim da revolta. Cf. Ibidem, 618-622).

${ }^{26}$ Como já referimos, Sigeu escreve 1521, mas depois acrescenta que a entrada foi no primeiro ano de reinado de D. João III, o que nos leva ao ano de 1522. Cf. "Relación..." in Amores Pérez, "Biografía de Luisa Sigea Toledana", 200.

${ }^{27}$ Ibidem, 201. Outra das figuras das Comunidades também acolhida sob a alçada do arcebispo de Braga foi Hernando de Ávalos (cf. Pérez, La révolution, 621), que terá falecido em Castelo Branco, a 4 ou 5 de Março de 1533, onde foi enterrado. Cf. María del Carmen Vaquero Serrano, "Hernando Dávalos", Real Academia de la Historia: Diccionario electrónico; http://dbe.rah.es/biografias/127835/hernando-davalos (consultado a 10 de Maio de 2019).

${ }^{28}$ Cf. Luís de Matos, "O ensino na corte durante a dinastia de Avis", in O bumanismo português 1500 1600: Primeiro Simpósio Nacional: 21-25 de Outubro de 1985 (Lisboa: Academia das Ciências, 1988), 536.

${ }^{29}$ Assinado em Valladolid em Janeiro de 1522, o Perdón General incluía elementos efectivamente nomeados e excluía outros. Para os excluídos, o perdão teria de ser comprado, como várias vezes sucedeu. Cf. Pérez, La révolution, 589-633. Diogo Sigeu é explícito nas suas palavras quando se refere aos servidores que obtiveram o perdão real por meios financeiros: «[...] que para todos los criados y paniaguados que con ella vinieron y se quisieron tornar a Castilla les hubo perdón conprado a dinero [...]» ("Relación..." in Amores Pérez, "Biografía de Luisa Sigea Toledana", 201).

${ }^{30}$ Recordemos que o pai de D. João prestara auxílio financeiro (e não só) a Carlos V e que o monarca Habsburgo demoraria a saldar essa dívida. Além disso, também D. Manuel não acedeu ao pedido de Carlos V, neste aspecto. Cf. João Paulo Oliveira e Costa, D. Manuel I (1469-1521): um príncipe do Renascimento (Lisboa: Temas e Debates, 2007), 364-365.

${ }^{31}$ Cf. Ana Maria Alves, "Comunicação e Silêncio num Diálogo Humanista (A propósito de Luísa Sigea)", in Comunicação e Silêncio. Textos de História, Política e de Circunstância (Lisboa: Livros Horizonte, 1990), 59; Prieto Corbalán, Luisa Sigea y su mundo, 45-46. 
Comunidades (onde se incluíam servidores da comunera), Carlos V nunca concedeu o perdão a D. María Pacheco.

Não havendo melhoras do seu estado de saúde, a mulher de Padilla mudou-se, novamente, para o Porto, albergando-se nas casas do bispo da cidade, D. Pedro da Costa. D. Pedro era capelão da infanta D. Isabel (1503-1539), filha de D. Manuel, desde 1521. Quando, em 1526, a irmã mais velha de D. João III casou com Carlos V, tornando-se imperatriz, o seu capelão acompanhou-a para Castela, onde alcançaria grande influência no meio cortesão. O bispo do Porto regressaria à diocese portuense apenas uma vez, em 1534, voltando, no mesmo ano, para a corte castelhana. Em Espanha, foi bispo de León, entre 1535 e 1539, e bispo de Osma, entre 1539 e 1563, ano da sua morte ${ }^{32}$. Era, portanto, uma figura que detinha algum poder nos círculos próximos da monarquia carolina.

Segundo Sigeu, D. Pedro da Costa tentou interceder por D. María Pacheco junto de Carlos V, por intermédio do confessor do monarca, a fim de obter um perdão régio para a comunera, mas sem sucesso. Por esta altura, apenas permaneciam a seu lado Diogo Sigeu, Diego de Figueroa, o bacharel Juan de Sosa (seu capelão) e «la más familia [que] tomó acá en Portugalı ${ }^{33}$. Sabemos que um dos seus irmãos, D. Diego Hurtado de Mendoza (1503/1504-1575), poeta e futuro embaixador castelhano em Itália, a terá visitado no Porto, a partir de finais de 1525 e talvez até à sua morte, mas Sigeu não nos dá qualquer registo desta visita na sua Relación ${ }^{34}$ (talvez para não comprometer o jovem Mendoza) $)^{35}$.

Terá sido nos últimos anos de vida da sua senhora que Diogo Sigeu começou a receber convites particulares para ensinar línguas clássicas. Enquanto esteve no Porto,

32 Para mais detalhes sobre a vida de D. Pedro da Costa, veja-se Cândido Augusto Dias dos Santos, "Actividade episcopal de D. Pedro da Costa em Portugal e em Espanha (1507-1563)", in D. Manuel e a sua época: actas do III Congresso Histórico de Guimarães (Guimarães: s. n., 2004), vol. II, 11-21.

33 "Relación..." in Amores Pérez, "Biografía de Luisa Sigea Toledana", 201.

${ }^{34}$ Falaremos sobre esta obra, que temos vindo a citar, posteriormente. Adiantamos, para efeitos esclarecedores, que o seu título completo é Relación sumaria del comienzo y suceso de las guerras civiles que llamaron las Comunidades de Castilla, de cuya causa se recogió la muy ilustre señora Doña María Pacheco, que fue casada con Juan de Padilla, a Portugal, [con quien yo Diego de Sygi vino] (doravante, mencionada apenas como Relación). Existem duas versões da obra: uma publicada por Luís de Matos, (cf. Luís de Matos, A Corte Literária dos Duques de Bragança no Renascimento [Lisboa: Fundação da Casa de Bragança, 1956], 39-41) e outra por Raúl Amores Pérez (cf. Amores Pérez, "Biografía de Luisa Sigea Toledana", 190-202). Sendo que a edição de Luís de Matos apresenta apenas um pequeno excerto da obra, servimo-nos maioritariamente da edição integral feita por Amores Pérez, salvo excepções devidamente assinaladas.

35 Nesta sua visita ao Porto, D. Diego Hurtado de Mendoza fez-se acompanhar por Mariangelo Accursio, um erudito italiano com ligações indirectas a Portugal. Cf. Amândio Barros, "Marinheiros em terra. Um estudo comparado dos quotidianos marítimos atlânticos no final da Idade Média e início da Época Moderna", in Construção Naval em Madeira. Arte, técnica e património. Atas do Congresso Internacional, 23-25 de maio/2016, coord. Amélia Polónia e Marta Miranda (Vila do Conde: Câmara Municipal, 2008), 226-228. Foi nesta estadia em Portugal que Hurtado de Mendoza conheceu o bispo de Viseu, D. Miguel da Silva, que voltara a Portugal, vindo de Roma, no ano de 1525. Apenas não temos conhecimento de quando terá deixado terras lusas, sendo uma possibilidade tê-lo feito após a morte da irmã, em 1531. Cf. Sylvie Deswarte-Rosa, Il "perfetto cortegiano" D. Miguel da Silva (Roma: Bulzoni Editore, 1989), 97; Ana Isabel Buescu, "D. João III e D. Miguel da Silva, bispo de Viseu: novas razões para um ódio velho", Revista de História da Sociedade e Cultura 10, tomo I (2010): 141-168. 
sabemos que Sigeu ensinou latim a alguns naturais, como Diogo Pires, mercador e cristão-novo, que, aquando da sua prisão pelo tribunal inquisitorial eborense, em 1544, declara ter aprendido essa língua clássica com o pai de Luísa Sigeia, durante «três ou quatro anos $\rangle^{36}$. A sua reputação ter-se-á espalhado oralmente, chegando a vários cantos do reino. Talvez, por isso, em 1530, D. María deu-lhe ordem de aceitação de um cargo na Casa de Bragança, a segunda mais poderosa do reino, para instruir os filhos do duque D. Jaime (1479-1532) ${ }^{37}$, IV titular da Casa. No ano seguinte, a saúde de D. María agravou-se rapidamente e a comunera redigiu o seu testamento, deixando expresso o desejo de ser enterrada na Sé do Porto e, quando a carne estivesse sumida, que os seus ossos se trasladassem para o sepulcro do marido, em Villalar ${ }^{38}$.

Sigeu esclarece que o capelão de D. María, Juan de Sosa, numa tentativa de concretizar esta sua última vontade, ainda antes de esta sucumbir à enfermidade que a minava, se dirigiu a Castela, solicitando esta diligência aos irmãos da comunera, D. Luis Hurtado de Mendoza (1489-1566), II marquês de Mondéjar ${ }^{39}$, e D. Bernardino Hurtado de Mendoza (1501-1557), mas os nobres não acederam ao seu pedido, voltando o capelão para o Porto, onde permaneceu, servindo a Sé. D. María Pacheco acabaria por morrer no exílio, no Porto, em Março de $1531^{40}$, sempre excluída dos perdões reais (desde 1522) e para sempre condenada à morte (desde 1524) ${ }^{41}$.

\subsection{Na corte da Casa de Bragança, em Vila Viçosa}

Quando Diogo Sigeu entrou ao serviço da Casa de Bragança, era ainda titular o duque D. Jaime ${ }^{42}$. Apesar de se ter vindo a repetir que os serviços do humanista se iniciaram em Vila Viçosa no ano de 1530, existe a possibilidade de essa data ser antecipada para o ano anterior, em 1529. A dúvida é incitada pelo próprio Diogo quando, na Relación, escreve que serviu D. Jaime «tres años, y despues 17 al Duque Don Theodosio mi señor, su hijo primogénito» ${ }^{43}$. Ora, D. Jaime faleceu em 1532, o que, contando os três anos que o humanista serviu o duque, demarca a data para o início desse serviço em 1529. É certo que poderá haver a hipótese de Sigeu se ter enganado, mas parece-nos

36 Matos, "O ensino na corte", 536.

${ }^{37}$ D. Jaime era filho do III duque de Bragança, D. Fernando (1430-1483), e de D. Isabel de Viseu (1459-1521), irmã do falecido rei D. Manuel I, o que fazia de D. Jaime primo directo de D. João III, rei de Portugal.

${ }^{38}$ Cf. "Relación..." in Amores Pérez, "Biografía de Luisa Sigea Toledana", 201-202.

39 Sobre D. Luis Hurtado de Mendoza, cf. Clara Marías Martínez, "Luces y sombras de un noble al servicio de Carlos V y Felipe II, el II Marqués de Mondéjar", in Spanische Kunst von El Greco bis Dali: Ambiguitäten statt Stereotypen (Arte Español desde El Greco a Dali. Ambiguëdades en lugar de estereotipos), coord. Michael Scholz-Hänsel, e David Sánchez Cano (Berlin: Frank \& Timme, 2014), 129-158.

${ }^{40}$ Cf. "Relación..." in Amores Pérez, "Biografía de Luisa Sigea Toledana", 202.

${ }^{41}$ Cf. Pérez, La révolution, 621-622; Barros, "Marinheiros em terra", 226-228.

${ }^{42}$ Sobre D. Jaime, cf. Matos, A Corte Literária; Maria de Lurdes Rosa, "D. Jaime, duque de Bragança: entre a cortina e a vidraça", in O Tempo de Vasco da Gama, dir. Diogo Ramada Curto (Lisboa: CNCDP / Difel, 1998), 319-332; Maria Paula Anastácio Gonçalves, A Senhora Duquesa e o Pajem. Um caso de adultério na aristocracia quinhentista (Lisboa: Chiado Editora, 2013); Paulo Catarino Lopes, "Depois de Vós. Duke Jaime de Braganza in the Confidence of King Manuel I", Tiempos Modernos 32 (2016): 35-50.

43 "Relación..." in Matos, A Corte Literária, 40. 
pouco provável, tendo em conta a forma como o escreve. Além disso, quando não tem certezas, Sigeu faz questão de o demonstrar explicitamente ${ }^{44}$.

Portanto, a proposta poderá ter sido feita em 1529 e Sigeu, depois de aceitá-la, poderá ter assentado - expressão verbal usada pelo próprio - em Vila Viçosa em $1530^{45}$. Assim, se o humanista aceitou a proposta do duque em 1529, mas só chegou a Vila Viçosa em 1530, então, os seus anos de serviço contariam a partir da aceitação do cargo e não da mudança para o Paço brigantino, certamente para atribuir mais prestígio a si próprio. Em suma, a sua actividade como professor dos filhos de D. Jaime poderá ter começado em 1529, mas apenas se materializou em 1530.

Admitindo a data de 1530 como o início da actividade prática de Diogo Sigeu como preceptor em Vila Viçosa, permanece uma dúvida: com uma plêiade de humanistas em florescimento pela Península Ibérica (e não só), por que recaiu a escolha de D. Jaime em Diogo, um nome pouco (re)conhecido, um homem que pertencera ao séquito de uma exilada política? A nossa hipótese sugere que talvez o seu nome não fosse totalmente desconhecido de D. Jaime, um duque educado na corte da culta Isabel a Católica. As circunstâncias dessa educação poderão ajudar-nos a perceber se, de facto, haveria algum tipo de ligação entre D. Jaime e Diogo. Vejamos esta possibilidade mais de perto.

Em 1483, D. Fernando, III duque de Bragança, marido de D. Isabel de Viseu e pai de D. Jaime, foi executado a mando do rei D. João II (1455-1495), obrigando a sua prole a exilar-se em Castela ${ }^{46}$, na corte de Isabel a Católica, no poder desde $1474^{47}$. Durante os treze anos que viveram exilados na corte castelhana, D. Jaime e o seu irmão mais novo, D. Dinis (1481-1516), foram educados num círculo de poder que não era o seu, numa corte humanista que albergava, por esses anos, a presença de intelectuais como Pedro Mártir de Anghiera (c. 1456-1526) e Lucio Marineo Sículo (c. 1444-1536) ${ }^{48}$, com quem o futuro duque de Bragança teve a sua formação inicial ${ }^{49}$. Ambos os mestres vieram de Itália para a corte isabelina pelas mãos de nobres que detinham poder e influência no núcleo próximo dos Reis Católicos, Isabel e Fernando. O primeiro foi trazido pelo conde de Tendilla, como já vimos, e o segundo veio no séquito do almirante de Castela, Fadrique Enríquez (1460-1538), futuro co-regente do reino, no período da revolta das Comunidades.

44 Por exemplo, quando diz que D. María Pacheco, quando no exílio, esteve três ou quatro anos em Braga, ou quando refere a morte da sua senhora, não se recordando do dia. Cf. "Relación..." in Amores Pérez, "Biografía de Luisa Sigea Toledana", 201-202.

45 Sigeu refere que estava ao serviço da corte brigantina um ano antes do falecimento de D. María, o que indica que estava, efectivamente, na cidade alentejana.

46 D. Jaime tinha apenas quatro anos.

${ }^{47}$ Isabel a Católica era sobrinha de D. Beatriz, a mãe da duquesa de Bragança, Isabel de Viseu, o que fazia delas primas. Por isso, a rainha castelhana era prima em segundo grau de D. Jaime.

48 Debruçamo-nos sobre esta figura mais adiante.

${ }^{49}$ Cf. A. Silva, "Algumas cartas a portugueses do século XVI (Livro II). Cataldo Parísio Sículo" (Dissertação de Mestrado, Faculdade de Letras da Universidade de Coimbra, 1992), 7; Ana Isabel Buescu, A livraria renascentista de D. Teodósio I, duque de Bragança (Lisboa: Biblioteca Nacional de Portugal, 2016), 230. 
Restaurada a Casa de Bragança por D. Manuel, em 1496, D. Jaime e D. Dinis regressaram a Portugal, onde continuariam os seus estudos, pelo menos D. Dinis, que foi discípulo de Cataldo Parísio Sículo (1455-1517?), na corte portuguesa ${ }^{50}$. Aqueles treze anos de educação na corte castelhana criaram ligações políticas, sociais e afectivas entre o jovem duque e vários elementos do círculo cortesão e humanista. Lucio Marineo Sículo poderá ser uma das ligações que D. Jaime manteve viva com o reino vizinho.

Sabemos que Cataldo Parísio foi professor de latim de D. Teodósio (1505?1563), filho do primeiro casamento do duque com D. Leonor de Mendoza (c. 1489?1512), filha dos duques de Medina Sidonia ${ }^{51}$, mas é também sabido que a educação dos nobres não se restringia a um único mestre, pelo que D. Jaime poderá ter procurado conselho junto dos seus antigos professores, nomeadamente Lucio Marineo Sículo, a fim de atribuir outros mestres a D. Teodósio e aos filhos do seu segundo casamento com D. Joana de Mendonça $(\dagger 1580)^{52}$. Sículo poderá ter indicado o nome de Sigeu ao duque $^{53}$, uma vez que o humanista de origem francesa, além de se encontrar em Portugal no pós-Comunidades, perdera aquele que seria, muito provavelmente, o seu primeiro aluno, Pero López de Padilla, filho único de D. María Pacheco, que falecera em 1523, e, por isso, estaria disponível para assegurar a educação humanística dos filhos de D. Jaime ${ }^{54}$.

Uma vez no Paço de Vila Viçosa, Diogo Sigeu começou por complementar a educação literária de D. Teodósio, ensinando-lhe grego e hebraico ${ }^{55}$. Em 1532, morreu D. Jaime, sucedendo-lhe na Casa o primogénito, D. Teodósio, como V duque de Bragança. O novo duque manteve Sigeu ao seu serviço, com a tarefa de preparar os seus irmãos para o futuro ingresso na Universidade ${ }^{56}$. O serviço prestado ao $\mathrm{V}$ duque de Bragança desenvolveu-se durante dezassete anos, permitindo a estabilização financeira tão necessária para a família de Sigeu e desenvolvendo uma reputação humanística que lhe permitiu garantir um futuro menos preocupado ${ }^{57}$.

${ }^{50}$ Cf. Matos, A Corte Literária, 14.

${ }^{51}$ D. Isabel de Velasco (†1496) e D. Juan de Guzmán (1464-1507), III duque de Medina Sidonia. O matrimónio celebrou-se nos primeiros anos de 1500, mas em virtude da curta idade de D. Leonor só foi consumado mais tarde.

52 D. Jaime e D. Joana casaram-se em 1520.

53 Sículo e Sigeu provavelmente conheceram-se em Burgos nos anos de 1511/1512. Cf. Monteiro, "Quando as sombras ofuscam a luz", 65-68.

${ }^{54}$ Além disso, Sigeu poderia ter boa reputação no seu meio, ou, pelo menos, desenvolveria bem o seu ofício, pois Sículo elogia os dotes linguísticos de D. María Pacheco, na sua obra De rebus Hispaniae memorabilius, publicada em 1530. Cf. Nieves Baranda, "Desterradas del Parnaso. Examen de un monte que solo admitió musas", Bulletin Hispanique 109, núm. 2 (2007): 433.

55 Complementando a formação em latim que o jovem recebera de Cataldo Parísio.

${ }^{56}$ Cf. Matos, A Corte Literária, 17; Buescu, A livraria renascentista de D. Teodósio I, 284.

${ }^{57}$ Os irmãos de D. Teodósio tiveram, portanto, uma sólida preparação humanista. D. Jaime estudou Cânones em Coimbra e tornou-se vice-reitor da mesma universidade, em 1537. D. Fulgêncio e D. Teotónio formaram-se no Colégio do Mosteiro de Santa Cruz, onde tiveram os mesmos mestres, e foram alunos no Colégio das Artes, onde tiveram professores como o prestigiado latinista Diogo de Teive. A formação universitária de D. Fulgêncio começou em Coimbra, onde se tornou «bacharel, licenciado e mestre em Artes em 1548-9» (Matos, A Corte Literária, 15) e bacharel em Teologia em 1556. 
Foi porventura durante estes anos em Vila Viçosa que Sigeu escreveu a sua Relación, relembrando os anos de serviço junto de D. María Pacheco, a quem o humanista dedicou a obra, compondo um epitáfio em latim ${ }^{58}$. Existem duas versões da obra, mas ambas servem o mesmo propósito: relatar os acontecimentos da revolta das Comunidades de Castela pela perspectiva de quem participou, de forma mais ou menos directa, na preparação da revolução. Diogo Sigeu foi um dos escolhidos para fazer um inventário das escrituras do Arquivo da Casa do Ayuntamiento de Toledo, referentes a queixas feitas, de tempos antigos, contra a imposição da alcabala ${ }^{59}$, documentos que queimou, posteriormente, em Portugal ${ }^{60}$. É também neste seu testemunho que ficamos a conhecer a relação próxima que mantinha com D. María Pacheco, pois Sigeu foi uma das pessoas que assistiu ao momento em que a sua senhora recebeu a notícia da detenção e execução de Juan de Padilla, em Abril de 1521.

Como esclarece Luís de Matos, a Relación tem duas versões, que poderão distar entre si alguns anos, ambas manuscritas e apenas uma delas com autoria ${ }^{61}$. A primeira versão foi, muito provavelmente, escrita em Vila Viçosa, entre 1539 e os anos da saída de Sigeu para a corte lisboeta. Encontra-se na Biblioteca do Escorial, em Madrid, e foi publicada pela primeira vez em 1879, por Rodríguez Villa, que atribuiu a sua possível autoria (o manuscrito está anónimo) a um secretário de D. María Pacheco ${ }^{62}$. Raúl Amores Pérez republicou-a, recentemente, na íntegra, completando-a com anotações de contexto ${ }^{63}$.

Esta versão (do Escorial) terá sido escrita depois de Sigeu ter aceite entrar ao serviço do duque de Bragança, D. Jaime, mas ainda sem perspectivas de futuro. Contudo, podemos apontar para uma data posterior a 1539, pois quando Diogo Sigeu se refere ao bispo do Porto, D. Pedro da Costa, que acolheu a comunera e o seu séquito, o pai das Sigeia esclarece que o mesmo «agora es Obispo de Osma» ${ }^{64}$, posição que D. Pedro ocupou entre 1539 e 1563, ano da sua morte ${ }^{65}$. Portanto, esta versão da Relación

Em 1573, fez o doutoramento na mesma área, mas na universidade de Lovaina. D. Teotónio, mais novo, tornar-se-ia arcebispo de Évora, obtendo, em 1559, o grau de mestre em Artes, no Collège de Bourgogne, e em 1574, o grau de doutor em Teologia, em Bordéus (cf. Ibidem, 15-16). Faça-se menção à notável biblioteca da Cartuxa de Évora, a quem D. Teotónio ofereceu a sua "“Livraria", constituída por livros impressos de edições raras, manuscritos gregos e livros chamados de sabedoria arábica, siríaca e de outras línguas orientais». M. Hespanhol, "Dom Theotónio de Bragança: o primeiro arcebispo de Évora no domínio filipino (1578-1602)" (Dissertação de Mestrado, Faculdade de Letras da Universidade de Lisboa, 1993), vol. I, 361.

58 Cf. Antonio Rodríguez Villa, "La viuda de Juan de Padilla. Relación histórica del siglo XVI", Revista Europea 256 (1879): 58, nota 1; Matos, A Corte Literária, 38; "Relación..." in Amores Pérez, "Biografía de Luisa Sigea Toledana", 202.

${ }^{59}$ Imposto; espécie de sisa.

${ }^{60}$ Esta sua participação aconteceu depois da formação da Junta, já com Juan de Padilla na liderança de Toledo. Cf. "Relación..." in Amores Pérez, "Biografía de Luisa Sigea Toledana", 193.

${ }^{61}$ Cf. Matos, A Corte Literária, 37-38.

${ }^{62}$ Cf. Rodríguez Villa, "La viuda de Juan de Padilla".

${ }^{63}$ Cf. "Relación..." in Amores Pérez, "Biografía de Luisa Sigea Toledana", 190-202.

${ }^{64}$ Ibidem, 201.

${ }^{65}$ Cf. Santos, "Actividade episcopal de D. Pedro da Costa", 13-14, 17-21. 
terá sido escrita quando Sigeu ainda estava em Vila Viçosa, na corte dos duques de Bragança (até 1549/1550).

A segunda versão poderá ter sido escrita já em Lisboa, entre 1549/50 e 1563, ano da morte do duque D. Teodósio. Esta segunda versão encontra-se na British Library, em Londres, com o título Memórias dos Sucessos de Portugal compilado por Fernão Duarte de Monterroyo ${ }^{66}$, sendo mais completa nos aspectos biográficos e profissionais do seu autor. Luís de Matos publicou um excerto desta versão, que inclui os vinte anos que Sigeu esteve ao serviço da Casa de Bragança ${ }^{67}$. É este dado - os vinte anos de serviço na corte de Vila Viçosa - que nos faz crer que esta segunda versão, posterior, terá sido escrita na corte régia, em Lisboa, e, por isso, fora do círculo cortesão da Casa de Bragança.

\section{4. $\mathrm{Na}$ corte régia, em Lisboa}

Durante duas décadas, Diogo Sigeu permaneceu em Vila Viçosa, ligado às letras e humanidades, ofício que viria a repetir em Lisboa. Em 1549/1550, D. João III convidou-o para professor dos seus moços-fidalgos, convite aceite pelo humanista ${ }^{68}$. Ao mesmo tempo (ou anteriormente), poderá ter sido um dos mestres do príncipe D. João $(1537-1554)^{69}$, o então único filho sobrevivente do casal real ${ }^{70}$, mas sem certezas ${ }^{71}$.

\footnotetext{
${ }^{66}$ Cf. British Library, Add. MS 20922: Memorias dos successos de Portugal, compiladas por Fernao Duarte de Monterroyo, fols. $18-22 \mathrm{v}$.

${ }^{67}$ Cf. Matos, A Corte Literária, 39-41.

${ }^{68}$ Não temos certezas quanto ao ano em que entrou ao serviço de D. João III, mas sabemos que, em 1551, já era mestre dos moços-fidalgos, tendo já um nome sonante na corte portuguesa. O documento que nos atesta esta informação refere-se a um dos seus filhos, António Sigeu de Velasco, nomeando-o escrivão da câmara, o que sugere que o pai, Diogo Sigeu, detinha já uma posição social de grande destaque no círculo de poder da corte. Cf. ANTT, Chancelaria de D. João III, Doacões e Mercês, liv. 66, fol. 248v. Surgindo no grupo dos letrados e físicos, Diogo auferia 375 reais de moradia. Cf. António Caetano de Sousa, Provas da História Genealógica da Casa Real Portuguesa (Lisboa: Sylviana, 1748), tomo VI, 620. O nome de Diogo Sigeu surge numa quadra de um poema escrito por Girolamo Britonio, impresso em Veneza, em 1550. Cf. Eugenio Asensio, "El italiano Britonio, cantor de la 'Lisboa de D. João III", in Arquivos do Centro Cultural Português (Paris: Fundação Gulbenkian, 1972), vol. V, 551. Britonio, poeta italiano, terá estado na corte portuguesa entre inícios de 1540 e até 1546, ano em que, em Roma, é publicado o seu poema sobre Lisboa, Ulysbonae regiae Lusitaniae vrbis carmen. Girolamo é o intermediário de Luísa, na sua entrega de cartas ao papa Paulo III. Cf. Monteiro, "Quando as sombras ofuscam a luz", 86-91.

${ }^{69}$ D. João viria a casar, em 1552, com Juana de Áustria (1537-1573), sua prima direita, filha da rainhaimperatriz D. Isabel de Portugal, irmã do seu pai, e de Carlos V, irmão da sua mãe. Deste casamento, nasceu D. Sebastião, único filho, póstumo.

${ }^{70}$ D. João III e D. Catarina de Áustria tiveram numerosa prole, mas foram-na perdendo para a morte consecutivas vezes, como acontecia, em simultâneo, com os irmãos do monarca. A única filha que chegara à adolescência, D. Maria, casada com Filipe, herdeiro da coroa castelhana, morrera de parto em 1545.

${ }^{71}$ Sabemos que, em 1545, o mestre do príncipe era D. António Pinheiro, de quem falaremos mais adiante. Cf. Ana Isabel Buescu, D. João III (1502-1557) (2 ${ }^{\text {a }}$ Edição. Rio de Mouro: Temas e Debates, 2008), 34. António Carvalho da Costa foi um dos autores que escreveu, erradamente, que Diogo Sigeu foi mestre do rei D. João, e não do príncipe:
} 
Foi também na corte de Lisboa que ensinou as filhas da infanta D. Isabel (a.15121576), irmã do duque D. Teodósio, casada com o infante D. Duarte (1515-1540), irmão de D. João III: as infantas-duquesas D. Maria (1538-1577) e D. Catarina (1540-1614) ${ }^{72}$ e o seu único varão, D. Duarte (1541-1576) ${ }^{73}$.

Após alguns anos de serviço na corte régia, onde terá recebido mercês ${ }^{74}$, Sigeu abandonou Lisboa e ter-se-á retirado para Torres Novas, em Santarém, em 1555, segundo tem repetido a historiografia (com a qual discordamos). Esta data foi fixada, primeiramente e de forma implícita, por Allut, que escreveu que, após treze anos de serviço, a família Sigeia, na corte desde 1542, se mudara para Torres Novas, apontando o ano de 1555 como o momento dessa mudança ${ }^{75}$. Por ser o estudo pioneiro sobre Luísa Sigeia, os dados de Allut foram seguidos por outros autores, perdurando até hoje $^{76}$. Contudo, temos certezas de que, pelo menos em 1556, Sigeu ainda permanecia em Lisboa, a ensinar os jovens da corte e outros que aguardavam filhamento ${ }^{77}$; por

«Foy seu pay [de Ângela Sigeia] Diogo Sigéo Mestre del-Rey D. Joaõ o Terceyro, \& do Duque de Bragança D. Theodosio, \& do senhor D. Duarte, \& da senhora D. Catherina, \& D. Maria Duqueza de Parma suas irmãas, filhas do Infante D. Duarte, \& depois o foy dos moços Fidalgos da Corte del-Rey D. Joaõ o Terceyro» (António Carvalho da Costa, Corografia Portugueza e Descripçam Topografica do famoso Reyno de Portugal, com as noticias das fundações das Cidades, Villas, \& Lugares, que contèm; Varões illustres, Genealogias das Familias nobres, fundações de Conventos, Catalogos dos Bispos, antiguidades, maravilhas da natureza, edificios, \& outras curiosas observações [Lisboa: Officina Real Deslandesiana, 1712], tomo III, 286).

Artur Gonçalves refere os outros eruditos que seguiram esta mesma ideia. Cf. Artur Gonçalves, Torrejanos Ilustres em letras, ciências, armas, religião, etc. (Torres Novas: Câmara Municipal de Torres Novas, 1933), 224-227.

72 A sua inscrição sepulcral atesta-o apenas como mestre da infanta D. Catarina (cf. Monteiro, "Quando as sombras ofuscam a luz", 213), mas podemos supor que também o foi da irmã, D. Maria, que «da lingua Grega teve bastante conhecimento». Cf. António Caetano de Sousa, História Genealógica da Casa Real Portuguesa (Lisboa: José António da Silva, 1737), tomo III, 446.

${ }^{73}$ Diogo Sigeu surge como mestre de latim no Rol de moradores da Casa do Senhor D. Duarte, filho do Infante D. Duarte: «Diogo de Sige Mestre de Latim» (Sousa, Provas da História Genealógica, tomo II [1742], 617-618).

${ }^{74}$ Apenas temos conhecimento de uma mercê de 25.000 reais, atribuída pela rainha a Diogo, mas que se destinavam à filha, Luísa, para o seu casamento com Francisco de Cuevas. Cf. ANT'T, CC, Parte I, mç. 88, doc. 100.

${ }^{75}$ Cf. Paul Allut, Aloysia Sygea et Nicolas Chorier (Lyon: N. Scheuring, 1862), 10-12.

${ }^{76}$ Excluindo os autores que não referem o ano desta mudança, seja explícita ou implicitamente, apenas Teresa Barros. Cf. Teresa Leitão Barros, Escritoras de Portugal: génio feminino revelado na literatura portuguesa (Lisboa: s.n., 1924), vol. I, 62 e Pérez Ramírez (cf. Pérez Ramírez, Tarancón en la Historia, 161) sugerem uma data diferente: 1554 e 1552, respectivamente. Amores Pérez confunde-nos quando, num primeiro momento, aceita a data de 1555 (cf. Amores Pérez, "Biografía de Luisa Sigea Toledana", 241), mas, mais tarde, indica o ano de 1552 para a ida da família para Torres Novas (cf. Amores Pérez, "Luisa Sigea de Tarancón y la Infanta Doña María de Portugal", 38). Os outros autores que consultámos seguem a data de 1555. Cf. Monteiro, "Quando as sombras ofuscam a luz", 43, nota 277.

77 António Caetano de Sousa publica o documento nas Provas da História Genealógica, mas não transcreve as notas que surgem no original (cf. Sousa, Provas da História Genealógica, tomo II, 382-384). No documento original, as anotações são feitas nas margens por uma segunda mão que continua o rol de apontadores com a nomeação dos «outros mossos fidalgos, que andão na Escolla e naõ vem neste Rol dos apontadores» (ANTT, Gavetas, Gav. 2, mç. 4, n 33). 
isso, a sua ida para Torres Novas teria acontecido mais tarde do que se tem vindo a reiterar. Os dados que apresentaremos adiante sustentam esta nossa hipótese.

Em 1557, pouco antes de falecer, D. João III encomendou-lhe aquela que seria a segunda obra do humanista, um Missal com 160 entradas $^{78}$. A encomenda, que o monarca não chegou a ver terminada, seria concluída em 1563, já sob a regência do cardeal-infante D. Henrique, o que significa que a produção do Missal se prolongou entre o final do reinado de D. João III, atravessou a regência da rainha D. Catarina (1557-1562) e se consumou nos primeiros anos do governo de D. Henrique. Tal só faria sentido se a obra - uma encomenda régia dedicada a uma pessoa régia - tivesse sido desenvolvida em ambiente cortesão, logo, se Sigeu residisse com a corte, em Lisboa. Além disso, o próprio autor esclarece que a feitura deste volume foi executada segundo as indicações de D. António Pinheiro (1510?-1582?) ${ }^{79}$, mestre do príncipe D. João ${ }^{80}$.

Apesar de, aparentemente, ter permanecido manuscrita, esta segunda composição do humanista foi ricamente adornada. Por fora, o Missal foi encadernado com marroquim ${ }^{81}$ vermelho e lavrado a ouro. No seu interior, os 173 fólios em pergaminho foram todos tarjados a ouro. As iniciais foram embelezadas com cores e ouro e o texto em duas colunas está povoado de «miniaturas e ornamentos iluminados, de uma harmonia e viveza de colorido admiráveis» ${ }^{82}$. Pelo meio, tem quase trinta fólios com «música» ${ }^{83}$ (leia-se, pautas musicais).

Não temos ideia do valor desta decoração (mais do que a obra), mas ostentava, claramente, e apesar de simples, uma pequena riqueza digna de uma biblioteca real. Em muitos dos casos, eram os elementos externos, ou melhor, os elementos complementares ao próprio livro, de que são exemplo as iluminuras, que lhe davam valor e não o seu conteúdo propriamente dito. Portanto quando a um livro, mesmo

78 Esta obra é mencionada apenas por Luís de Matos (cf. Luís de Matos, Les Portugais en France au XVT $T^{e}$ siècle. Études et Documents [Coimbra: Imprensa da Universidade, 1952], 112-113) e Prieto Corbalán (cf. Prieto Corbalán, Luisa Sigea y su mundo, 50-51), que recolheu o testemunho do livro do conde de Tovar, que mencionaremos adiante. O título completo da obra é o seguinte: Sacerdotale volumen ad ritum Sanctae Romanae Ecclesiae scriptum. In quo babentur CXL Missae: quibus Portugal. Reges interesse soleniter consuevere prae Epistolas, et Evangelia quae separatim sunt de industria excripta, ad faciliorem Subdiacc. ac Diaconor usum, emendata omnia exactiss. Pientiss. Iobãnis III Regis Ductu atque imperio.

${ }^{79}$ Sobre António Pinheiro, cf. Buescu, D. João III, 259; e Conde de Tovar, Catálogo dos Manuscritos Portugueses ou relativos a Portugal existentes no Museu Britânico (Lisboa: Academia das Ciências, 1932), 305.

${ }^{80}$ No título do prefácio do Missal, o humanista apelida-se «Diegus Sygeus Toletanus Senion», uma nomenclatura interpretada por María R. Prieto Corbalán como prova de que o seu filho primogénito, que recebera o mesmo nome, era conhecido no mundo letrado e que poderia, tal como o pai, escrever, o que obrigava a uma distinção entre os dois. Cf. Prieto Corbalán, Luisa Sigea y su mundo, 50.

81 Proveniente de Marrocos (ou de outras partes da Berberia), o marroquim era pele de cabra tingida de várias cores (azul, amarelo ou vermelho), destinada a forrar ou encadernar objectos. Cf. Rafael Bluteau, Vocabulario portuguez e latino, aulico, anatomico, architectonico, bellico, botanico, brasilico, comico, critico, chimico, dogmatico, dialectico, dendrologico, ecclesiastico, etymologico, economico, florifero, forense, fructifero... autorizado com exemplos dos melhores escritores portugueses, e latinos... (Coimbra: Colégio das Artes da Companhia de Jesus, 1727), vol. V, 344.

82 Tovar, Catálogo dos Manuscritos Portugueses, 306.

83 Ibidem, 306. 
que manuscrito, se acrescentavam elementos decorativos ricos, o seu valor aumentava, sendo que o trabalho dessa decoração traduzia a vontade régia da exaltação do poder. Assim, entende-se que a encomenda de D. João III nunca tenha sido esquecida pela Coroa, mesmo quando esta passou por e para outras mãos, o que indica que o seu autor esteve, de forma contínua, senão mesmo permanente, nos círculos da corte.

No entanto, estes dados não chegam para afirmar, com certezas, que Diogo Sigeu permaneceu em Lisboa até 1563. Contudo, temos outras informações que apontam para fortes indícios de que, de facto, o humanista não se mudou de forma permanente para Torres Novas nos anos de 1550.

Ainda antes de terminar o Missal, Sigeu publicou uma outra obra (a terceira ${ }^{84}$ ), impressa na tipografia régia de João Blávio, a 13 de Setembro de 1560, na cidade de Lisboa $^{85}$, com o seguinte título: De ratione accentuum, commatum, colorum, sectionum, ac diversorum apicum: quibus Regiae Portugalliae Capellae libri denuo recogniti, atque emendati, in lucem prodeunt, Diego Sygaeo Toletano observatore ${ }^{86}$. Esta, uma espécie de gramática, serviria como uma adenda a uma futura reedição do Missal encomendado por D. João III e de outros livros litúrgicos, segundo esclarece Luís de Matos ${ }^{87}$. A acompanhar o texto latino do pequeno livro, dedicado ao sereníssimo príncipe ${ }^{88}$, o cardeal-infante D. Henrique, surgem apontamentos de caracteres hebraicos, manuscritos a preto e vermelho. Segundo Barbieri, o estudioso que apresentou a obra de Sigeu ao mundo, neste opúsculo, o humanista teve a ajuda de, pelo menos, dois oficiais da capela real na correcção dos textos litúrgicos: Bartolomeu Trosiglio (Trosilho ${ }^{89}$ ) e Em. (Emílio?) Cardoso, mestre de coro e director de canto, respectivamente ${ }^{90}$.

Durante estes anos na corte, Sigeu poderá ter conhecido vários nomes do humanismo europeu que por lá passaram e com quem terá contactado de forma próxima. Até nós, apenas chegaram dois registos desses contactos. Trata-se de duas cartas latinas, ambas assinadas em Lisboa, uma delas praticamente desconhecida da historiografia, que nos fornecem dados muito específicos sobre o momento da sua redacção.

${ }^{84}$ Já aqui referenciámos esta obra, aquando da formação universitária do pai das Sigeia.

85 Pelo menos, a dedicatória foi firmada nesta data, em Lisboa. Cf. Manuel Serrano y Sanz, Apuntes para una biblioteca de escritoras españolas desde el año 1401 al 1833 (Madrid: Establecimiento tipográfico "Sucesores de Rivadeneyra", 1905), vol. II, 395.

86 Alguns excertos foram publicados em: Asenjo Barbieri, "Una obra de Diego Sigeo".

87 Cf. Matos, Les Portugais en France, 112. Prieto Corbalán segue a mesma ideia, sem, porém, referenciar o autor. Cf. Prieto Corbalán, Luisa Sigea y su mundo, 50.

88 A dedicatória presente no cólofon é a seguinte: «Ad Serenissimum Principem Enricum, Portugalliae Infantem, Sanctae Romanae Ecclesiae Cardinalem». Na primeira folha, escrito à mão, lê-se: «Pera o Cardeal Infante» (Asenjo Barbieri, "Una obra de Diego Sigeo", 54; Serrano y Sanz, Apuntes para una biblioteca, 395).

${ }^{89}$ Segundo Hugo Teles Porto, em 1535, Bartolomeu Trosilho recebia uma tença anual de 3 moios de trigo. Cf. H. Porto, "Os cantores na administração nos reinados de D. Manuel I e de D. João III" (Dissertação de Mestrado, Faculdade de Ciências Sociais e Humanas da Universidade Nova de Lisboa, 2014), 166.

${ }^{90}$ Cf. Asenjo Barbieri, "Una obra de Diego Sigeo", 54-55; Prieto Corbalán, Luisa Sigea y su mundo, 51. 
A primeira, datada de 1561, foi endereçada a Jean Nicot (1530-1600), embaixador francês na corte portuguesa entre 1559 e 1561, de quem o humanista terá sido próximo ${ }^{91}$. Essa carta $^{92}$ seguiu acompanhada do poema de Luísa Sigeia, que enaltece a paisagem de Sintra, nome que coroa a composição poética. Junto ao poema, foram também enviados vários epigramas dedicados à poliglota, que falecera no ano anterior, a 13 de Outubro de 1560. Nesta epístola, Sigeu explica que, três dias antes, tentara entregar-lhe pessoalmente o poema da filha e despedir-se do amigo, mas que o pajem de Nicot the dissera que o embaixador estava ocupado com a sua correspondência diplomática, pelo que o humanista, depois de aguardar um pouco, desistiu do contacto.

Passados os referidos três dias, e sabendo Diogo que o diplomata iria partir brevemente, decidiu escrever-lhe esta carta, sendo muito directo nas suas palavras:

Así pues, he aquí la obrita de la pequeña alma de nuestra Sigea. Te pido a ti, hombre ilustrísimo, que, como me prometiste, decidas librarte de la aversión que tienes a la travesía [...], con la lectura de la obrita. Luego que atraques sano y salvo en Francia, lo que espero y pido a Dios, procura dar a conocer dicha obrita. Adiós, y que seas feliz ${ }^{93}$.

Nota-se, nestas palavras do humanista, com alguma clareza, a proximidade entre os dois interlocutores. Ao que parece, Nicot sabia da existência do Syntra, o poema da filha poliglota do amigo, mas ainda não o tivera em mãos ${ }^{94}$. Sigeu ter-lhe-á entregue uma reprodução manuscrita, talvez até feita por si (à falta de mais cópias), acompanhando-a com os referidos epigramas.

A resposta a esta carta, escrita também em latim, foi assinada por Nicot, em Paris, no primeiro de Junho de $1566^{95}$. Nela, o embaixador fazia saber ao amigo que o poema da sua filha, «tu Luisa, mi Sigea» ${ }^{96}$, o deleitou durante a sua viagem até França. O diplomata francês pretendia devolver a obra de Sigeia ao pai, com anotações de $\mathrm{Cl}$. Monselli, nome alatinado de Claude Monsel, «el más experto de los oradores» ${ }^{97}$. Pelas suas palavras, o poema da erudita terá causado impacto em terras francesas: «Procura que la Infanta doña María aprecie esta opinión en lo que vale, pues nunca se sostuvo en Francia un juicio de tal clase con respecto a una criada suya» ${ }^{98}$. Por fim, Nicot

\footnotetext{
${ }^{91}$ Cf. Matos, Les Portugais en France, 109, 113-115.

92 "Carta de Diego Sigeo a Jean Nicot" (01.10.1561) in Prieto Corbalán, Luisa Sigea y su mundo, 152.

93 Ibidem, 152.

${ }^{94}$ Seria Nicot quem iria publicar, pela primeira vez, o Syntra, em 1566. Sobre as várias edições do poema de Luísa, cf. Carolina Michaëlis Vasconcelos, A Infanta D. Maria de Portugal (1521-1577) e as suas damas (3a Edição. Lisboa: Instituto da Biblioteca Nacional e do Livro, 1994 [1902]), 88, nota 154; C. Pinto, "O Mecenato da Infanta Dona Maria de Portugal (1521-1577)" (Dissertação de Mestrado, Faculdade de Ciências Sociais e Humanas da Universidade Nova de Lisboa, 1996), vol. 1, 138, nota 450; J. Pereira Gomes, "Sigeia (Luísa)", in Verbo. Enciclopédia Luso-Brasileira de Cultura (Lisboa / São Paulo: Editorial Verbo, 2003), tomo 26, 1105-1006.

${ }^{95}$ Cf. "Carta de Jean Nicot a Diego Sigeo" (01.06.1566) in Prieto Corbalán, Luisa Sigea y su mundo, 152-153.

96 Ibidem, 152.
${ }^{97}$ Ibidem, 152.
${ }_{98}$ Ibidem, 152.
} 
felicitou Sigeu por ter resgatado o nome da filha de um aparente esquecimento que, para ele, nunca seria permanente, graças ao zelo com que Luísa ocupara o seu estudo, que o embaixador classificou como «amor pelas letras»:

Luisa, mi Sigea, ha nacido de nuevo gracias a ti, aunque en verdad antes nunca murió del todo. Vivirá innumerables siglos gracias a la belleza exquisita de ese arte que ella cultivó con tanto cello. Y ahora, como una antorcha aún más resplandeciente, [ela, Luísa] ilumina a las mujeres hispanas y a todas las demás con su asombroso amor a las letras ${ }^{99}$.

Não sabemos, porém, se Diogo recebeu esta resposta de Nicot, nem temos conhecimento de que ela tenha sido sequer enviada. Pensamos que poderá ter ficado, desde sempre, em terras francesas, onde foi publicada por Cerdà y Rico nos finais do século XVIII ${ }^{100}$ e por Allut, em meados do século XIX ${ }^{101}$. As razões para essa conservação em França são, por nós, desconhecidas, mas podem prender-se com a morte de Diogo Sigeu. Talvez o diplomata francês tenha tido conhecimento do falecimento do amigo e, não tendo ligações pessoais que justificassem o envio da carta, deixou-a por expedir, fazendo-a cair no olvido ${ }^{102}$.

A segunda carta que temos de Sigeu, assinada a quatro dias dos idos de Fevereiro de $1562^{103}$ (dia 10), foi endereçada a Miguel de Cabedo (1525-1577) ${ }^{104}$ e escrita no último ano da regência de D. Catarina. Como referimos, esta carta é quase ignorada pela historiografia, talvez por ser difícil de encontrar ${ }^{105}$. Foi impressa na

\footnotetext{
${ }^{99}$ Ibidem, 152-153.

100 Cf. Francisco Cerdà y Rico, Clarorum Hispanorum Opuscula Selecta et Rariora tum latina, tum bispana, magna ex parte nunc primum in lucem edita (Madrid: António de Sancha, 1781), 258.

${ }^{101}$ Cf. Allut, Aloysia Sygea, 6. É a partir desta edição que Prieto Corbalán faz a edição traduzida para castelhano, que aqui seguimos.

$102 \mathrm{O}$ poema, pelo contrário, foi impresso nesse ano em Paris e reeditado algumas vezes.

103 «Dat. Olysipponen. iiij. Idus Febr. ann. salut. M. D. LXII» (André de Resende, De Antiquitatibus Lusitaniae Libri Quattuor (Roma: Bernardo Basa, 1597 [1593]), 515).

104 Miguel de Cabedo era filho de D. Teresa Pinheiro, irmã do bispo de Viseu, D. Gonçalo Pinheiro, e de Jorge de Cabedo, embaixador na corte francesa. Era irmão de João Pinheiro, que esteve presente no Concílio de Trento. Teve formação superior nas universidades de Bordéus e Tolosa, mas também em Coimbra, nos anos de 1540, onde foi discípulo de Martín Azpilcueta Navarro (1492-1586). Depois de Coimbra, voltou a França, passando pelas universidades de Orleães e Paris, onde publicou a primeira de várias obras, em 1547. Em 1554, já se encontrava em Portugal, ano da publicação de uma outra obra sua, em Coimbra. Em 1559, tomou posse do cargo de Desembargador da Casa da Suplicação e, em 1565, foi nomeado ouvidor dos feitos crimes da mesma Casa. Cf. Maria do Rosário de Sampaio Themudo Barata de Azevedo Cruz, As regências na menoridade de D. Sebastião. Elementos para uma história estrutural (Lisboa: INCM, 1992), vol. 1, 157, 158, 169. Em 1575, terá sido nomeado Desembargador dos Agravos. Casou com D. Leonor Pinheiro, sua prima materna direita, de quem teve numerosa prole. Cf. Diogo Barbosa Machado, Bibliotheca Lusitana: historica, critica e cronologica na qual se comprehendea noticia dos authores Portuguezes, e das Obras, que compuzeraõ desde o tempo da promulgaçã da Ley da Graça até o tempo prezente (Lisboa: Ignacio Rodrigues, 1752), tomo III, 467-469.

105 Prieto Corbalán, por exemplo, refere esta carta na sua lista epistolar, mas não a edita. Muito provavelmente, teve conhecimento dela na bibliografia que consultou, mas não teve acesso à carta propriamente dita. Cf. Prieto Corbalán, Luisa Sigea y su mundo, 49, 51, 88.
} 
segunda edição da De Antiquitatibus Lusitaniae de Resende ${ }^{106}$, de onde fizemos a transcrição ${ }^{107}$, e, segundo Sousa Viterbo, numa outra obra editada por um familiar de Miguel de Cabedo ${ }^{108}$.

Com a conclusão do Missal encomendado por D. João III, em 1563, terminam os registos da vida do humanista, de quem não conhecemos mais nenhum escrito, epistolar ou de outro tipo. Poderá ter falecido nos anos entre 1563, data do término do Missal (achamos que será o mais provável), e 1566, ano da resposta de Jean Nicot e da primeira publicação do Syntra em França. Tendo em conta de que terá nascido nos finais do século XV, não seria de esperar que sobrevivesse muito para além destes anos.

Todos estes apontamentos foram assinados em Lisboa, o que pode significar que Diogo Sigeu permaneceu na capital, junto da corte, durante os últimos anos da sua vida ${ }^{109}$. A sua ida para Torres Novas ${ }^{110}$, comummente fixada em 1555, pode, por isso, ter servido apenas e só para fixar residência para a filha, Ângela, que por lá terá casado, e onde baptizou a sua descendência ${ }^{111}$. Talvez por isso, Diogo Sigeu tenha escolhido ser sepultado na igreja do convento do Carmo, em Torres Novas, ao lado da mulher, D. Francisca de Velasco ${ }^{112}$, e de uma neta, Maria Magdalena de Velasco, filha de Ângela ${ }^{113}$.

\section{ALGUMAS CONCLUSÕES}

A narrativa biográfica que aqui desenhámos não traduz certezas absolutas, mas demonstra algumas possibilidades, refutando ideias pré-estabelecidas e desenvolvendo novas hipóteses sobre a figura de Diogo Sigeu. A releitura dos dados que eram já

106 Cf. Resende, De Antiquitatibus Lusitaniae, 514-515. Mencionada por Vasconcelos, A Infanta D. Maria de Portugal, 89, n. 161; e Matos, Les Portugais en France, 111.

107 Cf. Monteiro, "Quando as sombras ofuscam a luz", 202.

${ }^{108}$ Cf. Francisco de Sousa Marques Viterbo, "Isabel Carreira. A mãe de Fr. Bartholomeu Ferreira. A mulher de Antonio de Sygy de Velasco", in Arquivo Histórico Português (Lisboa: Tip. Calçada do Cabra, 1903), vol. I, 76, nota 1. A obra, assinada por Gonçalo Mendes de Vasconcelos e Cabedo, intitula-se Diversorum juris argumentorum e foi impressa em Coimbra, por António de Barreira, em 1594. Foi publicada uma segunda edição em Roma, em 1598. Infelizmente, não conseguimos encontrar a carta em nenhuma das edições desta obra.

${ }^{109}$ Silva Dias considera que o Missal e a «gramática» foram da autoria do filho de Diogo, com o mesmo nome. Cf. Dias, A política cultural, 340.

110 Mencione-se, a título de curiosidade, que a Câmara Municipal de Torres Novas atribuiu o apelido das filhas de Diogo - Sigea - a uma rua, relativamente próxima do centro da cidade.

111 Sobre a descendência de Ângela, que se prolongou até ao início do século XX, cf. Monteiro, "Quando as sombras ofuscam a luz", 142-151.

112 Artur Gonçalves refere, mais do que uma vez, que Francisca jaz sepultada no jazigo do marido, na igreja do Carmo de Torres Novas, o mesmo jazigo onde foi sepultada a sua neta, D. Maria Magdalena de Velasco, filha de Ângela. Cf. Gonçalves, Torrejanos Ilustres, 228-229, 232, 234, 496; e Costa, Corografia Portugueza, tomo III, 287.

113 Depois da trasladação dos ossos de Diogo Sigeu, verificou-se que, na sua sepultura, encontravamse ossadas de mais duas pessoas, possivelmente a mulher e uma neta do humanista. Cf. Gonçalves, Torrejanos Ilustres, 230-234. 
conhecidos, a análise de informações complementares e a identificação e permutação dos silêncios documentais que se impõem permitiram uma reorganização cronológica da vida deste humanista. Dessa reorganização, importa destacar a vivência e ligações ao meio cortesão, laços que Sigeu desenvolveu desde os seus tempos de aluno na universidade de Alcalá de Henares, em Espanha, e que preservou até ao fim da vida, já em Portugal. Os contactos que criou na universidade, onde se formou com os melhores professores, homens da elite cultural, e onde conviveu com colegas que, no decorrer dos tempos, se tornariam humanistas de renome, permitiram-lhe tornar-se preceptor de D. María Pacheco e iniciar uma carreira pedagógica que, por força das circunstâncias, viria a cumprir em Portugal. A sua participação na revolta das Comunidades também não deverá passar despercebida. Relembramos que, nas duas versões da sua Relación, Sigeu refere que teve, pelo menos, uma intervenção activa, que passou pela inventariação de uma série de papéis que, mais tarde, viria a queimar em Portugal. No entanto, e exactamente devido ao seu relato, sabemos que Diogo esteve em permanente contacto com os bastidores da rebelião, denunciando a sua proximidade com o movimento, que fica clara quando acompanha a sua senhora no exílio para terras lusas.

Esta ligação ao poder (D. María não deixava de ser filha do conde de Tendilla, marquês de Mondéjar e vice-rei de Granada) manter-se-ia por largos anos e potenciaria a sua veia pedagógica. Ainda no exílio, no Porto, Sigeu continuava a ensinar latim e grego, até 1529/1530. Mais tarde, fá-lo-ia em Vila Viçosa, na corte dos duques de Bragança, D. Jaime e D. Teodósio, seu filho. Aí, ensinaria também os seus próprios filhos, que cresceriam, portanto, em ambiente cortesão e humanista. Vinte anos mais tarde, em 1549/1550, mudar-se-ia para a corte do rei de Portugal, D. João III, para educar os moços-fidalgos do paço real. Seria também mestre dos filhos do infante D. Duarte e da infanta-duquesa D. Isabel (entre eles a futura candidata ao trono D. Catarina, correspondente de Ângela Sigeia). Foi também em Lisboa que fez imprimir, nos anos de 1560, uma das suas obras, dedicadas a membros da Casa real, e onde terá escrito a segunda versão da sua Relación. O afastamento perante a corte só aconteceria aquando da sua morte.

Assim, os dados que reunimos para Diogo ajudam a corroborar uma vivência cortesã própria e, principalmente, muito próxima da Casa real portuguesa. Estes revelam a personalidade de um homem que viveu da e para a corte, preferindo, contudo, os bastidores que envolviam o estudo, prática e ensino das letras aos palcos da política portuguesa de Quinhentos. Desta forma, o percurso de Sigeu revelar-se-ia basilar para a integração de Luísa na corte portuguesa e essencial para a construção da identidade humanista da sua filha, cuja ligação ao universo cortesão antecederia, e muito, a sua própria existência enquanto mulher. 


\section{REFERENCIAS BIBLIOGRÁFICAS}

\section{Fontes Manuscritas}

ANTT, Arquivo Distrital de Lisboa, Registos Paroquiais, Paróquia de São Salvador (Torres Novas), Mistos núm. 2 (1569-1588).

ANTT, Corpo Cronológico, Parte I, mç. 88, doc. 100.

ANTT, Chancelaria de D. João III, Doações e Mercês, lv. 66, fol. 248v.

ANTT, Gavetas, Gav. 2, mç. 4, núm. 33.

British Library, Add. MS 20922: Memorias dos successos de Portugal, compiladas por Fernao Duarte de Monterroyo, fols. 18-22v.

\section{Fontes Impressas}

Bluteau, Rafael, Vocabulario portuguez, e latino, aulico, anatomico, architectonico, bellico, botanico, brasilico, comico, critico, chimico, dogmatico, dialectico, dendrologico, ecclesiastico, etymologico, economico, florifero, forense, fructifero... autorizado com exemplos dos melhores escritores portugueses, e latinos...., vol. V (Coimbra: Colégio das Artes da Companhia de Jesus, 1727).

Cerdà y Rico, Francisco, Clarorum Hispanorum Opuscula Selecta et Rariora tum latina, tum hispana, magna ex parte nunc primum in lucem edita (Madrid: António de Sancha, 1781).

Costa, António Carvalho da, Corografia Portugueza e Descripçam Topografica do famoso Reyno de Portugal, com as noticias das fundaçôes das Cidades, Villas, \& Lugares, que contèm; Varões illustres, Genealogias das Familias nobres, fundações de Conventos, Catalogos dos Bispos, antiguidades, maravilhas da natureza, edificios, \& outras curiosas observações, tomo III (Lisboa: Officina Real Deslandesiana, 1712).

Fernández Bethencourt, Francisco, Historia genealógica y heráldica de la monarquía española, Casa Real y Grandes de España, tomo III (Madrid: Establecimiento Tipográfico de Enrique Teodoro, 1901).

Machado, Diogo Barbosa, Bibliotheca Lusitana: historica, critica e cronologica na qual se comprehendea noticia dos authores Portuguezes, e das Obras, que compuzeraõ desde o tempo da promulgaçaõ da Ley da Graça até o tempo prezente, tomo III (Lisboa: Ignacio Rodrigues, 1752). 
Resende, André de, De Antiquitatibus Lusitaniae Libri Quattuor (Roma: Bernardo Basa, 1597 [1593]).

Sigeu, Diogo, De ratione accentuum, commatum, colorum, sectionum, ac diversorum apicum: quibus Regiae Portugalliae Capellae libri denuo recogniti, atque emendati, in lucem prodeunt, Diego Sygaeo Toletano observatore (Lisboa: João Blávio, 1560).

Sigeu, Diogo, Sacerdotale volumen ad ritum Sanctae Romanae Ecclesiae scriptum. In quo habentur CXL Missae: quibus Portugal. Reges interesse soleniter consuevere prae Epistolas, et Evangelia quae separatim sunt de industria excripta, ad faciliorem Subdiacc. ac Diaconor usum, emendata omnia exactiss. Pientiss. Iohãnis III Regis Ductu atque imperio (Lisboa: s. n., 1563).

Sousa, António Caetano de, História Genealógica da Casa Real Portuguesa, tomo III (Lisboa: José António da Silva, 1737).

Sousa, António Caetano de, Provas da História Genealógica da Casa Real Portuguesa, tomos II e IV (Lisboa: Sylviana, 1742 e 1748).

\section{Estudos}

Allut, Paul, Aloysia Sygea et Nicolas Chorier (Lyon: N. Scheuring, 1862).

Álvarez-Cifuentes, Pedro, "Juego de damas: una corte femenina en el quinhentismo portugués", in Las Revolucionarias: literatura e insumisión femenina, ed. lit. Estela González de Sande e Ángeles Cruzado Rodríguez (Sevilha: Arcibel Editores, 2009), 41-58.

Alves, Ana Maria, "Comunicação e Silêncio num Diálogo Humanista (A propósito de Luísa Sigea)", in Comunicação e Silêncio. Textos de História, Politica e de Circunstância (Lisboa: Livros Horizonte, 1990), 57-84.

Amores Pérez, Raúl, "Biografía de Luisa Sigea Toledana. Una taranconera del siglo XVI en la corte portuguesa y española", in Melchor Cano y Luisa Sigea: dos figuras del Renacimiento Español, coord. Miguel Ángel Pérez Priego (Tarancón: Ayuntamiento de Tarancón / UNED, 2008), 167-265.

Amores Pérez, Raúl, "Luisa Sigea de Tarancón y la Infanta Doña María de Portugal: «amiticia» entre desiguales, aprendizaje en común", in Catálogo de Obras de Luisa Sigea de Velasco, Virginia Garrido de la Torre (trad.), Raúl Amores Pérez e Jesús Garrido Gallego, eds. (Tarancón: Ayuntamiento de Tarancón, 2017), 11-42. 
Arranz Márquez, Luis, "Pedro Mártir de Anglería", Real Academia de la Historia: Diccionario electrónico; http://dbe.rah.es/biografias/10770/pedro-martir-deangleria (consultado a 10 de Maio de 2019).

Asenjo Barbieri, Francisco, "Una obra de Diego Sigeo", Boletín Histórico 4 (1880): 5355.

Asensio, Eugenio, "El italiano Britonio, cantor de la 'Lisboa de D. João III'", in Arquivos do Centro Cultural Português (Paris: Fundação Gulbenkian, 1972), vol. V, 546-559.

Backer, Stephanie Fink de, "Rebel with a Cause: The Marriage of María Pacheco and the Formation of the Mendoza Identity", in Power and Gender in Renaissance Spain. Eight Women of the Mendoza Family, 1450-1650, ed. Helen Nader (Urbana and Chicago: University of Illinois Press, 2004), 71-91.

Baranda, Nieves, "De investigación y bibliografía. Con unas notas documentales sobre Luisa Sigea", $\quad$ Lemir $10 \quad$ (2006), http://parnaseo.uv.es/Lemir/Revista/Revista10/Baranda/BARANDA.htm (consultado a 10 de Maio de 2019).

Baranda, Nieves, "Desterradas del Parnaso. Examen de un monte que solo admitió musas", Bulletin Hispanique 109, núm. 2 (2007): 421-447. https://doi.org/10.3406/hispa.2007.5297

Baranda, Nieves, "Luisa Sigea: la brillante excepción femenina", in Melchor Cano y Luisa Sigea: dos figuras del Renacimiento Español, coord. Miguel Ángel Pérez Priego (Tarancón: Ayuntamiento de Tarancón / UNED, 2008), 129-152.

Barros, Amândio Jorge Morais, "Marinheiros em terra. Um estudo comparado dos quotidianos marítimos atlânticos no final da Idade Média e início da Época Moderna", in Construção Naval em Madeira. Arte, técnica e património. Atas do Congresso Internacional, 23-25 de maio/2016, coord. Amélia Polónia e Marta Miranda (Vila do Conde: Câmara Municipal, 2008), 205-239.

Barros, Teresa Leitão, Escritoras de Portugal: génio feminino revelado na literatura portuguesa, vol. I (Lisboa: s.n., 1924).

Bourdon, Léon e Odette Sauvage, "Recherches sur Luisa Sigea", in Bulletin des Études Portugaises (Lisboa: Institut Français au Portugal, 1970), vol. XXXI, 33-176.

Buescu, Ana Isabel, "D. João III e D. Miguel da Silva, bispo de Viseu: novas razões para um ódio velho", Revista de História da Sociedade e Cultura 10, tomo I (2010): 141-168. http://dx.doi.org/10.14195/1645-2259_10-1_6. 
Buescu, Ana Isabel, A livraria renascentista de D. Teodósio I, duque de Bragança (Lisboa: Biblioteca Nacional de Portugal, 2016).

Buescu, Ana Isabel, D. João III (1502-1557), 2a edição (Rio de Mouro: Temas e Debates, 2008).

Costa, João Paulo Oliveira e, D. Manuel I (1469-1521): um principe do Renascimento (Lisboa: Temas e Debates, 2007).

Curz, Maria do Rosário de Sampaio Themudo Barata de Azevedo, As regências na menoridade de D. Sebastião. Elementos para uma história estrutural (Lisboa: INCM, 1992).

Deswarte-Rosa, Sylvie, Il "perfetto cortegiano" D. Miguel da Silva (Roma: Bulzoni Editore, 1989).

Dias, José Sebastião da Silva, A política cultural da época de D. João III, vol. I (Coimbra: Imprensa da Universidade, 1969).

García Casar, María Fuencisla, "Alonso de Zamora", Real Academia de la Historia: Diccionario electrónico; http://dbe.rah.es/biografias/6393/alonso-de-zamora (consultado a 10 de Maio de 2019).

García Rámila, Ismael, "Nuevas e interesantes noticias, basada en fe documental, sobre la vida y descendencia familiar burgalesa de la famosa humanista, Luisa de Sigea, la «Minerva» de los renacentistas", in Boletín de la Institución Fernán Gonzálę XXXVIII, núm. 144 (1958): 309-321; XXXVIII, núm. 145 (1959): 465-492; XXXVIII, núm. 147 (1959): 565-593.

Gomes, J. Pereira, "Sigeia (Luísa)", in Verbo. Enciclopédia Luso-Brasileira de Cultura (Lisboa / São Paulo: Editorial Verbo, 2003), tomo 26, 1105-1006.

Gomez Molleda, María Dolores, "La cultura femenina en la epoca de Isabel la Catolica. Cortejo y estela de una reina", Revista de Archivos, Bibliotecas y Museos, tomo LXI, núm. 1 (1955): 137-195.

Gonçalves, Artur, Torrejanos Ilustres em letras, ciências, armas, religião, etc. (Torres Novas: Câmara Municipal de Torres Novas, 1933).

Gonçalves, Maria Paula Anastácio, A Senhora Duquesa e o Pajem. Um caso de adultério na aristocracia quinhentista (Lisboa: Chiado Editora, 2013). 
Hespanhol, M., "Dom Theotónio de Bragança: o primeiro arcebispo de Évora no domínio filipino (1578-1602)" (Dissertação de Mestrado, Faculdade de Letras da Universidade de Lisboa, 1993), vol. I.

Jiménez Calvente, Teresa, "Hernán Núñez de Guzmán", Real Academia de la Historia: Diccionario electrónico; http://dbe.rah.es/biografias/21505/hernan-nunez-deguzman (consulta a 10 de Maio de 2019).

Lopes, Paulo Catarino, "Depois de Vós. Duke Jaime de Braganza in the Confidence of King Manuel I", Tiempos Modernos 32 (2016): 35-50, http://www.tiemposmodernos.org/tm3/index.php/tm/article/view/503/63 4 (consultado a 10 de Maio de 2019).

Manzano García, M., "Revisión de las noticias sobre libros, imprentas, bibliotecas y archivos, dadas por Antonio Ponz en su obra: viage [sic] de España", Papeles Salmantinos de Educación 2 (2002): 183-215.

Mareñà, I., "Luisa Sigea de Velasco: reflexions filosòfiques d'una docta puella espanyola del segle XVI" (Tese de Doutoramento, Universitat de Girona, 2014).

Marías Martínez, Clara, "Luces y sombras de un noble al servicio de Carlos V y Felipe II, el II Marqués de Mondéjar", in Spanische Kunst von El Greco bis Dali: Ambiguitäten statt Stereotypen (Arte Español desde El Greco a Dali. Ambiguëdades en lugar de estereotipos), coord. Michael Scholz-Hänsel, e David Sánchez Cano (Berlin: Frank \& Timme, 2014), 129-158.

Matos, Luís de, "O ensino na corte durante a dinastia de Avis", in O bumanismo português 1500-1600: Primeiro Simpósio Nacional: 21-25 de Outubro de 1985 (Lisboa: Academia das Ciências, 1988).

Matos, Luís de, A Corte Literária dos Duques de Bragança no Renascimento (Lisboa: Fundação da Casa de Bragança, 1956).

Matos, Luís de, Les Portugais en France au XVTe siècle. Études et Documents (Coimbra: Imprensa da Universidade, 1952).

Monteiro, C., "Quando as sombras ofuscam a luz. Luísa e Ângela Sigeia: estórias e histórias de vida no Portugal de Quinhentos" (Dissertação de Mestrado, Faculdade de Ciências Sociais e Humanas, Universidade Nova de Lisboa, 2019).

Pérez Ramírez, Dimas, Tarancón en la Historia. I. Desde la Romanización hasta el final del Antiguo Régimen (Tarancón: Antona, 1994). 
Pérez, Joseph, José Antonio Maravall, e Julio Valdeón Baruque, "Los comuneros", Historia 1624 (1978): 67-94.

Pérez, Joseph, La révolution des "Comunidades" de Castille (1520-1521) (Bordeaux: Institut d'Études Ibériques et Ibero-Americaines de l’Université, 1970).

Pinto, C., "O Mecenato da Infanta Dona Maria de Portugal (1521-1577)" (Dissertação de Mestrado, Faculdade de Ciências Sociais e Humanas da Universidade Nova de Lisboa, 1996).

Porto, H., "Os cantores na administração nos reinados de D. Manuel I e de D. João III" (Dissertação de Mestrado, Faculdade de Ciências Sociais e Humanas da Universidade Nova de Lisboa, 2014).

Prieto Corbalán, María Regla, Luisa Sigea y su mundo: epistolario latino (Madrid: Akal, 2007).

Rallo Gruss, Asunción, La prosa didáctica en el siglo XVI (Madrid: Taurus, 1987).

Rodríguez Villa, Antonio, "La viuda de Juan de Padilla. Relación histórica del siglo XVI", Revista Europea 255 (1879): 33-36; 256 (1879): 55-58.

Rosa, Maria de Lurdes, "D. Jaime, duque de Bragança: entre a cortina e a vidraça", in O Tempo de V asco da Gama, dir. Diogo Ramada Curto (Lisboa: CNCDP / Difel, 1998), 319-332.

Santos, Cândido Augusto Dias dos, "Actividade episcopal de D. Pedro da Costa em Portugal e em Espanha (1507-1563)", in D. Manuel e a sua época: actas do III Congresso Histórico de Guimarães (Guimarães: s. n., 2004), vol. II, 11-21.

Serrano y Sanz, Manuel, Apuntes para una biblioteca de escritoras españolas desde el año 1401 al 1833, vol. II (Madrid: Establecimiento tipográfico "Sucesores de Rivadeneyra", 1905).

Silva, A., "Algumas cartas a portugueses do século XVI (Livro II). Cataldo Parísio Sículo" (Dissertação de Mestrado, Faculdade de Letras da Universidade de Coimbra, 1992).

Teyssier, Paul, "L'Humanisme portugais et l'Europe", in L' Humanisme Portugais et l' Europe. Actes du XXIe Colloque International d'Études Humanistes (Paris: Fondation Calouste Gulbenkian / Centre Culturel Portugais, 1984), 821-845.

Tovar, Conde de, Catálogo dos Manuscritos Portugueses ou relativos a Portugal existentes no Museu Britânico (Lisboa: Academia das Ciências, 1932). 
Vaquero Serrano, María del Carmen, "Hernando Dávalos", Real Academia de la Historia: Diccionario electrónico; http://dbe.rah.es/biografias/127835/hernando-davalos (consultado a 10 de Maio de 2019).

Vasconcelos, Carolina Michaëlis de, A Infanta D. Maria de Portugal (1521-1577) e as suas damas, $3^{a}$ edição (Lisboa: Instituto da Biblioteca Nacional e do Livro, 1994 [1902]).

Viterbo, Francisco de Sousa Marques, "Isabel Carreira. A mãe de Fr. Bartholomeu Ferreira. A mulher de Antonio de Sygy de Velasco", in Arquivo Histórico Português (Lisboa: Tip. Calçada do Cabra, 1903), vol. I, 74-79.

Recibido: 12 de junio de 2019

Aprobado: 22 de julio de 2019 